\title{
Prolegomenon to an Informational Philosophy in Reality ${ }^{\dagger}$
}

\author{
Joseph E. Brenner ${ }^{1, *}$ and Abir U. Igamberdiev ${ }^{2}$ \\ 1 International Center for the Philosophy of Information, Xi'an Social Sciences University, \\ Xi' an 710049, China \\ 2 Department of Biology, Memorial University of Newfoundland, St. John's, NL A1B 3X9, Canada; \\ a_igamberdiev@hotmail.com \\ * Correspondence: joe.brenner@bluewin.ch \\ † Fourth International Conference on Philosophy of Information, Berkeley, CA, USA, 2-6 June 2019. \\ Published: 6 June 2020
}

\begin{abstract}
In the acceptation of Wu Kun, the Philosophy of Information is a metaphilosophy incorporating informational-philosophical stances on major epistemological and ontological questions. Examples of Brenner's contributions to previous Philosophy of Information conferences include work on personal identity, symmetry, semiotics, social competence and responsibility, as well as, together with $\mathrm{Wu}$, the informational revolution in philosophy itself. In this approach, the necessity of a non-standard logic of real processes was demonstrated. In this paper, Brenner and Igamberdiev analyze the dialectics and logic underlying the application of Informational Philosophy. The utility of their approach is further demonstrated in the areas of meaning and semiotics, as well as information itself and communication. A new characterization of dynamic units of thought, and hence of information processes, is suggested in advance of a planned, more detailed treatment.
\end{abstract}

Keywords: dialectics; epistemon; information; logicinreality; natural philosophy; ontolon; semiotics

\section{Introduction}

Philosophy, science and logic are systems of thought devised by human beings to describe their world and what it means to exist in it. Throughout history in the classical West, and to a certain extent in the East, there was no separation between the disciplines. However, the value of philosophy, especially today in the West, has been diminished by several major errors: the work of Aristotle and other classical Greeks, as well as later Western European thinkers, has been misused and misunderstood, without proper attention being paid to necessary corrections and extensions made possible by modern science. The value of dialectics as the basis of reasoning, and the need for a logic based in science rather than language, are major examples. In the last 100 years, phenomenology and semiotics have been proposed as a means of bridging the gap between knowledge and reality, but all suffer from reliance on the epistemic principles of classical linguistic logic. Dialectics, particularly as expressed by Hegel, was diverted from its initial objectives and used to support limited political-economic idealism and ideologies.

This paper defines a philosophy of, and in, reality that effects a 'rejunction' with some less familiar insights of Aristotle and recovers them to serve the current social objectives of the emerging information society. Aristotle gives the basis not only for modern bivalent linguistic logic, but also for a logic that refers to actualizations and potentialities in a physical world of processes. We will propose an extension and development of, and to, the second logic of Aristotle that is grounded in modern physics. This makes possible an understanding of real processes in terms of what is essentially a non-Boolean logic. We refer to two little known authors whose thought is 
essential to our thesis: the Russian Evald Ilyenkov and the Franco-Romanian Stéphane Lupasco. New concepts of the real dynamics of consciousness, creativity and ethics emerge from a study of these authors, making it possible to reread the work of Western figures such as Spinoza, Kant, Peirce, Whitehead, and Heidegger and, in relation to quantum physics, Heisenberg.

Our logic of real processes, Logic in Reality (LIR) [1], redefines the ontological relations between meaning, communication and language as components of a Philosophy in Reality (PIR). Under the influence of current developments in the science and philosophy of information, as noted by the Chinese thinker $\mathrm{Wu}$ Kun [2,3], a new, more functional convergence of science and philosophy is taking place. The resulting 'dialectical realism' may make possible a more ethical development of knowledge for the common good.

\section{The Scope of Philosophy in Reality}

Our definition of reality is not provable or acceptable to all or most people (see Colin McGinn [4] on the 'basic structures' of reality and the earlier concept of D'Espagnat of a 'veiled reality'). We insist on the existence of the dialectic between reality and appearance, as well as the operation of the mind moving from one to the other according to the Principle of Dynamic Opposition. Our philosophy of/in reality is not, and is not intended, to be a 'philosophy of everything'. It does not cover transcendental philosophy or philosophy based on beliefs about the origin or a possible purpose of the universe. What characterizes such positions in general is their reference to an inaccessible un-reality, sometimes expressed by the first and last letters of the Greek alphabet, alpha and omega.

We limit the scope of our Philosophy in Reality to the content of natural philosophy, as it is currently being redefined by Schroeder and Dodig-Crnkovic [5] as well as Brenner and others. The potentially useful criterion, which Brenner has proposed for delimiting natural philosophy from philosophy as a whole, is its logic [6]: the Logic in Reality. For the prolegomenon to an integral paradigm of natural philosophy written by Igamberdiev see [7].

\section{Logic in Reality (LIR)}

Brenner has discussed the principles of Logic in Reality and their derivation from the logical system proposed by Lupasco, in articles on consciousness [8], ecology [9] and natural philosophy [9], for example. Underlying this work is a vision of Lupasco's Principle of Dynamic Opposition (PDO) as operative in nature. We reproduce from [1] the best and simplest expression of this principle: "The antagonistic dualities of our world can be formalized as a structural, logical, and metaphysical principle of opposition or contradiction instantiated in complex higher-level phenomena (Principle of Dynamic Opposition-PDO). The fundamental postulate of LIR is that all energetic phenomena (all phenomena) alternate between degrees of actualization and of potentialization of themselves and their opposites or 'contradictions' but without either going to the absolute limits of $0 \%$ or $100 \%$. The point traversed at which a logical element and its opposite are equally actualized and potentialized is one of maximum interaction, from which new entities can emerge". It is designated by Lupasco and Basarab Nicolescu, the physicist colleague and major continuator of Lupasco [10], as a ' $\mathrm{T}$ '-state, $\mathrm{T}$ standing for included middle or third (Tiers-inclus).

\section{Information and the Laws of Thermodynamics}

The discussion of complex real processes still suffers from the lack of an appropriate language that takes into account both intrinsic and relational properties of a system at the same time. Deacon defines constraints as relational properties, but LIR amplifies this by using the rules for their evolution of potential as well as actual aspects. Ulanowicz [11] has made an extension of the Deacon approach by connecting concepts of entropy to the Third as well as the Second Law of Thermodynamics, in order to define entropy in relation to a degree of system constraint (actuality) and its conjugate state of residual freedom of interpretation of the Third Law, thus delivering 
meaning. In a picture of entropy and information, whose terms are always relative, this implies that, like those of quantum physics, they do not commute [12].

Igamberdiev further develops the idea that the Third Law of Thermodynamics is more important for understanding life than the Second Law, which is considered the basis of Prigogine's dissipative structures. The Third Law establishes the reference state with the lowest entropy, in relation to which the order (described as information) can be referred [13,14]. Rapoport was the first to suggest describing the stability of genetic structures by introducing special thermodynamic principles explaining the maintenance of low entropy in living systems $[15,16]$. This could be sufficient for mental Lupascian T-states, with a corresponding non-Boolean logic, as a possible physical precondition.

\section{Meaning and Convergence of the Science and Philosophy of Information}

Wu's definition of the role of information in philosophy is the critical first step in the characterization of the complex phenomenon of information and information processes. Wu's classification provides a basis for understanding a key current development: the convergence of Information Science and the Philosophy of Information as the precursor of an emergent Unified Science of Information [17]. This convergence is obviously not intended to imply an 'end' to philosophy or its conflation with science. Philosophy will continue to explore issues that arise, in particular, in relation to language and knowledge in their aspects as unique cognitive products of the human condition, with substantial abstract content. However, the question of the relation of that condition to the rest of the world logically requires retaining the scientific properties of that world to insure the validity of the comparison.

There is thus a set of new and unique relationships that are developing between the classical disciplines of science and philosophy as a consequence of new understandings of the science and philosophy of information. The overall movement is that of a philosophization of science and a scientification of philosophy, leading to their convergence.

\section{Epistemons and Ontolons}

The proposal of Logic in Reality outlined above and in [18] emerges from the still unknown ground of the universe, position and energy, or statics and dynamics, and can be rigorously described in dialectical terms as two different, opposing but non-separable aspects of that ground [19]. Digital bits, now part of knowledge, are an emergent epistemological phenomenon-the 'Bit-from-It' position, and the overall situation can be described by an 'onto-epistemology'. For this purpose, it is useful to maintain the two domains of ontology and epistemology, where the latter the concept of 'epistemons' has been proposed by James Barham [20,21]. The 'pieces' of the former will be called 'ontolons'. These two sets of entities could be supplemented by a third referring to the domain of the standard philosophy of being, but this issue is outside the scope of this paper.

\section{Summary and Conclusions}

The spirit of this paper emphasizes process rather than products; our 'conclusion' is not final but a pointer toward processes leading to further and better descriptions of reality. Our description here of reality and its philosophy assumes certain schemes of valid reasoning based on reasoning as an ontological as well as epistemological process. The reasoning can still be formal or informal. Formal reasoning has proven to be a powerful tool for understanding our world. However, the application of formal reasoning, like any human cognitive process, is partly informal and cannot be fully grasped in terms of formal logic alone. This process is dialectical, in that if different solutions are present at the same time the optimal one is chosen.

Conflicts of Interest: The authors declare no conflict of interest.

\section{References}

1. Brenner, J. Logic in Reality; Springer: Berlin/Heidelberg, Germany, 2008. 
2. $\mathrm{Wu}, \mathrm{K}$. The Interaction and Convergence of the Philosophy and Science of Information. In Proceedings of the 2nd International Conference on the Philosophy of Information, Vienna, Austria, 6 June 2015.

3. Wu, K.; Brenner, J. The Informational Stance: Philosophy and Logic. Part I: The Basic Theories. Log. Log. Philos. 2013, 22, 1-41.

4. McGinn, C. Basic Structures of Reality. Essays in Meta-Physics; Oxford University Press: Oxford, UK, 2011; p. 174.

5. Dodig-Crnkovic, G.; Schroeder, M. Contemporary Natural Philosophy and Philosophies. Philosophies 2018, 3, 42.

6. Brenner, J. The Naturalization of Natural Philosophy. Philosophies 2018, 3, 41.

7. Igamberdiev, A.U. Time and life in the relational universe: Prolegomena to an integral paradigm of natural philosophy. Philosophies 2018, 3, 30.

8. Brenner, J. Consciousness as Process: A New Logical Perspective. APA Newsl. 2018, 18, 10-22.

9. Brenner, J. The Philosophy of Ecology and Sustainability: New Logical and Informational Dimensions. Philosophies 2018, 3, 16.

10. Nicolescu, B. Nous, la Particule et le Monde; Editions du Rocher: Paris, France, 2002; (Originally published in Paris: Éditions Le Mail, 1985).

11. Ulanowicz, R. Towards Quantifying a Wider Reality: Shannon Exonerata. Information 2011, 2, $624-634$.

12. Rosen, R. Complexity as a system property. Int. J. Gen. Syst. 1977, 3, 227-232.

13. Davies, P.C.W. Does quantum mechanics play a non-trivial role in life? Biosystems 2004, 78, 69-79.

14. Rapoport, I.A. Microgenetics; Nauka: Moscow, Russia, 1965. (In Russian)

15. Igamberdiev, A.U.; Shklovskiy-Kordi, N.E. The quantum basis of spatiotemporality in perception and consciousness. Prog. Biophys. Mol. Biol. 2017, 130, 15-25.

16. $\mathrm{Wu}, \mathrm{K}$. The Interaction and Convergence of the Philosophy and Science of Information. Philosophies 2016, $1,228$.

17. Diaz Nafria, J.; Zimmermann, R.E. Emergence and Evolution of Meaning. Triple-C 2013, 11, $13-35$.

18. Brier, S. Cybersemiotics. In Why Information is not Enough; University of Toronto Press: Toronto, ON, Canada, 2008.

19. Brenner, J. Levels of Abstraction; Levels of Reality. In Luciano Floridi's Philosophy of Technology; Springer: Berlin/Heidelberg, Germany, 2012.

20. Barham, J. A Poincaréan Approach to Evolutionary Epistemology. J. Soc. Biol. Struct. 1990, 13, $193-258$.

21. Barham, J. A dynamical model of the meaning of information. Biosystems 1996, 38, 235-241.

(C) 2020 by the authors. Licensee MDPI, Basel, Switzerland. This article is an open access article distributed under the terms and conditions of the Creative Commons Attribution (CC BY) license (http://creativecommons.org/licenses/by/4.0/). 